\title{
RETINOPATHY OF PREMATURITY - A BULGARIAN PERSPECTIVE OF A GLOBAL EPIDEMIC
}

\author{
Elena Grozeva ${ }^{1}$, Jana Simova ${ }^{2}$, Desislava Vankova ${ }^{3}$, Zlatina Naneva ${ }^{4}$, Christina Grupcheva $^{2}$ \\ ${ }^{1}$ Medical Center - Galabovo \\ ${ }^{2}$ Department of Ophthalmology and Visual Sciences, Medical University of Varna \\ ${ }^{3} A C R O$, Medical University of Varna \\ ${ }^{4}$ Regional Health Inspectorate - Stara Zagora
}

\begin{abstract}
INTRODUCTION: Retinopathy of Prematurity (ROP) is in the focus of public health interest as far as it is one of the most common potentially avoidable causes of visual loss in childhood and can lead to vision impairment and blindness. Therefore, it has lifelong implications for the affected children, their families, but also for the whole society. In Bulgaria, the processes of continuous health care transformations have led to lower quality control over ROP-screening processes.

AIM OF THE STUDY: The aim of the presented study is to make a horizon scanning research, which includes: 1) introduction of some ROP-related definitions; 2) a clinical and public health overview of ROP from an international and Bulgarian perspective; 3 ) presentation of the organizational structure of screening, the early diagnosis and therapy of ROP in Bulgaria followed by public health recommendations.

MATERIAL AND METHODS: The methods used are: a literature review of global and national data on ROP; postal survey - questionnaire distributed amongst the ophthalmologists who diagnose and treat ROP and participatory research method e.g. a follow-up of the patients' path, the clinical and the public health procedures.

RESULTS AND DISCUSSION: Globally, the three waves of the ROP-epidemic are described. Nationally, the Bulgarian ROP-related picture is drawn, summarizing and analyzing the results from the interviews with ophthalmologists engaged in ROP-screening from all 28 administrative regions of Bulgaria (Period: April-September, 2015). Finally, after an extensive drill-down of the Bulgarian context and the global developments, locally relevant health policy strategies are proposed, like a development of a National Consensus on ROP and Registry database of ROP in Bulgaria. Further, a three-level ROP-screening procedure is outlined and the telemedicine application is grounded.
\end{abstract}

Keywords: retinopathy of prematurity, epidemiology, Bulgaria

\footnotetext{
Address for correspondence:

Jana Simova

Department of Ophthalmology,

Medical University of Varna

55 Marin Drinov Str.,

Varna, 9000

e-mail: janasimova@abv.bg
}

Received: February 5, 2016

Accepted: April 21, 2016

\section{INTRODUCTION}

ROP is characterized with abnormal blood vessels, which are fragile and can leak (leakage syndrome). Those vessels can also proliferate together with connective tissue (proliferation syndrome). ROP is classified in five stages, ranging from mild (stage I) to severe (stage V). Most babies who develop ROP have stages I or II. However, in a small number of babies, ROP takes a turn for the worse, some- 
times very rapidly. Another pathological process is scarring of the retina and subsequent retinal detachment. Retinal detachment is the main cause of visual impairment and total blindness in ROP (1). The clinicians dealing with ROP are in a challenging situation. The effects of what is or is not done now become apparent only months to years later (2). Untreated ROP threatens to destroy vision. The smaller a baby is at birth, the more likely that baby is to develop ROP. Therefore, the standards and definitions, related to prematurity need to be clear. Today, with the advances in neonatal care, smaller and more premature infants are being saved. Obviously, these infants are at a much higher risk for ROP.

Globally, ROP is in the focus of public health interest as far as it is one of the most common potentially avoidable causes of visual loss in childhood and can lead to lifelong vision impairment and blindness. ROP has lifelong implications for the affected children, their families, but also for the whole society. In Bulgaria, the processes of continuous health care transformations lead to lower control over ROPscreening processes. Therefore, our aim is to make a horizon scanning research, which includes: 1) introduction of some ROP-related definitions; 2) a clinical and public health overview of ROP from an international and Bulgarian perspective; 3) presentation of the organizational structure of the early diagnosis and treatment of ROP in Bulgaria, followed by public health recommendations.

\section{MATERIALS AND METHODS}

The research strategy was based on a literature review of global and national data on ROP in order to investigate this preventable visual loss as a public health issue. Further, to identify the national public health challenges-related to ROP, a postal survey was carried out amongst the specialists who are engaged in monitoring, diagnostics and treatment of ROP in the 28 administrative regions in Bulgaria (within the period of April-September, 2015). A participatory research method e.g. a follow-up of the patients' path and the clinical and public health procedures related to ROP has been applied. This was possible only through the close collaboration with the Regional Health Inspectorate of Stara Zagora. The questionnaire was designed especially for the survey and included five questions requiring information on ROP- related activities - screening, diagnostics and treatment. Hereafter, the information received from the questionnaire is summarized and analyzed.

On the bases of the research and the following discussion about the reasons for the "third epidemic" (3) of ROP, locally relevant health policy strategies are proposed for management of the ROP control, which ensure that all babies at risk are examined in order to avoid any preventable visual loss. The idea is to build a bridge between public health and clinical practice, supporting it with facts and evidence-based recommendations and national public health guidelines, which should support the processes of screening, diagnosing and treating ROP.

\section{Definitions Related to ROP}

There is no unified definition of a preterm baby. Nearly every country has its own standards. Therefore, the WHO-definition of preterm birth is presented: “...babies born alive before 37 weeks of pregnancy are completed...” Sub-categories of preterm birth, based on weeks of gestational age are defined as follow: Extremely preterm ( $<28$ weeks); Very preterm ( 28 to $<32$ weeks); Moderate to late preterm ( 32 to $<37$ weeks). Note: Births at 37 to 39 weeks still have suboptimal outcomes, and induction or cesarean birth should not be planned before 39 completed weeks unless medically indicated (4). The USA standards (5) of premature infant/preterm neonates are: weighing about 1250 grams ( $23 / 4$ pounds) or less and born before 31 weeks of gestation (A full-term pregnancy has a gestation period of 38-42 weeks). In Bulgaria, the medical standards were changed in 2014 and a premature baby is defined as such based on the weight at birth - up to 2499 grams and/or the duration of pregnancy up to 37 weeks of gestation (6).

The ROP-screening has a direct contribution to the health of the individual e.g. the preterm neonates and at its initial level is a kind of 'case-finding' process. Herewith the ROP-screening methods are defined:

Direct ophthalmoscopy is a method of examination of the fundus directly using a handheld instrument which provides erect, virtual image of the retina. The field of view is only $5^{0}$, and stereoscopic vision for the examiner is not possible (7).

Binocular indirect ophthalmoscopy (BIO) produces an inverted and reversed real image on the 
Elena Grozeva, Jana Simova, Desislava Vankova et al.

proximal side of a handheld condensing lens, onto which the examiner accommodates. It is a widely used method for posterior segment examination because of its large field, depth of focus, stereopsis, good illumination, and ease of use with scleral indentor (a device used to facilitate examination of the retinal periphery) (7). The conventional method, which is also accepted as the gold standard, for ROP screening is BIO with scleral indentation. ROP screening with this technique is difficult, particularly in developing countries, because it requires a specialized pediatric ophthalmologist experienced in ROP screening (8).

The RetCam (Clarity Medical Systems), a retinal wide-field digital imaging system (WFDI), allows documentation of large parts of the retina of the alert infant within minutes. The advantage of this method is that it can be performed by a trained nurse or midwife (9-12).

By definition, Telemedicine is "the use of electronic information and communications technologies to provide and support health care when distance separates the participants (13). Telemedicine combined with WFDI offers the opportunity for improved ROP screening by expert evaluation of the images independent of the screening site (14).

\section{ROP - Epidemiology and Screening}

ROP is a public health challenge as far as it affects long-term physical health with a higher risk of blindness, high myopia or strabismus. These effects exert a heavy burden on families, society and the health system (15). Around 25\% of all extremely preterm babies are affected by ROP. There is a risk also in moderately preterm babies especially if the oxygen therapy is overdosed and poorly monitored.

Global Information- The Three Waves of the ROP-Epidemic

Every year, about 15 million babies are born prematurely - more than one in 10 of all babies born around the world (4). The worldwide prevalence of blindness due to ROP is approximately 50,000. Most studies report ROP incidence about $60 \%$ for babies less than $1500 \mathrm{~g}$ (16). In the industrialized world, ROP is the cause for $15 \%$ of the blindness, while in middle- and low-income countries it causes $60 \%$ of the blindness (17).

ROP was a major cause of blindness in the USA and Western Europe 50-60 years ago. This occurred because all preterm infants were given $100 \%$ oxygen whether they needed it or not. Oxygen has a specific "toxicity" to the blood vessels, including those in the retina. After the role of oxygen was understood, and it was used less freely, blindness from ROP declined dramatically. Until very recently ROP was, therefore, seen as a condition of the West, and an iatrogenic problem that had been solved. Nowadays, ROP has become a public health issue in the developing world also.

In the Western world there have been two, identified in the academic literature, notable epidemics over the past 60 years. Severe ROP (initially termed "retrolental fibroplasia") was first diagnosed in 1942 during an epidemic of the disease in the 1940s (18). It was suggested in 1951 that the toxic effects of uncontrolled supplemental oxygen to newborns were the reason for the epidemic (19). As a result of controlled oxygen administration this epidemic ceased. For example, in the United States alone, the proportion of blindness due to ROP fell from 50\% in 1950 to $4 \%$ by 1965 (20). Unfortunately, this decline was accompanied by an increase in neonatal deaths from atelectasis and respiratory distress secondary to hyaline membrane disease (21). The late 1970s and 1980s were the period of the second ROP-epidemic $(22,23)$, which was similar in size to the first despite the careful monitoring of oxygen delivery to neonates since the 1950s. This second wave of ROP-epidemic was due to increased survival rates of very low birthweight premature infants weighing 750-999g and not to new iatrogenic factors (24). Survival rates for premature infants less than 27 weeks gestation continued to improve in the 1990s and, while some studies showed greater occurrence of more severe ROP, 24 more recent reports indicate a decline in incidence, severity, and progression in the developed countries. ROP remains prevalent in very low birthweight infants, with as many as $12.5 \%$ of infants born between 23 and 26 weeks gestation requiring treatment (25).

Over the last 10-15 years it has become clear that the incidence and prevalence of ROP is rising again and is a major cause of blindness in children in middle-income countries in Latin America, Eastern Europe and the emerging economies of South-Eastern Asia. It has been increasingly reported in China and India. The third wave of ROP-epidemics has been identified (3). This is happening because the ex- 
panding neonatal care in these countries is without adequate experience with screening and managing ROP. Rates of ROP requiring treatment also tend to be higher in middle- and low-income countries suggesting that babies are being exposed to risk factors which are, to a large extent, controlled in industrialized countries.

The screening for ROP in the United States is organized in the following way: the premature neonates are examined for ROP if they have a birth weight of less than or equal to $1500 \mathrm{~g}$ or a gestational age of 30 weeks or less. Selected infants with a birth weight between $1500 \mathrm{~g}$ and $2000 \mathrm{~g}$ or a gestational age at birth of greater than 30 weeks with an unstable clinical course should also have an eye exam (26). The UK ROP screening guidelines are as follows: "All babies less than 31 weeks gestational age (up to 30 weeks and 6 days) or less than 1251g birthweight must be screened for ROP. One criterion need to be fulfilled to meet the criteria for inclusion in the screening" (27). Extensive meta-analysis of worldwide guidelines suggests that if all infants with a gestational age of 30 weeks and 6 or 7 days or less (regardless of birth weight), as well as any infant with a birth weight of $1250 \mathrm{~g}$ or less are screened, the likelihood of an unscreened infant developing advanced stage ROP, for which treatment should be offered, is extremely low (25).

Regional Information - Bulgaria - Situations and Challenges

Globally, in the last three decades, epidemiologic studies have made fundamental contributions to the understanding of the etiology and management of blindness and low vision, respectively of ROP (28). Nowadays, ROP is a leading cause of preventable childhood blindness in middle-income countries (1). In the former Soviet Bloc countries, the incidence of severe ROP varies between prosperous and middleincome countries (16). Nationally, there are only regional studies, which provide data on ROP epidemiology in Bulgaria (29,30). However, lack of systematic data on preterm birth and related ROP at a country level has hampered public health policy in Bulgaria.

There are 67585 infants born in Bulgaria in 2014; of those, 6349 are premature. The medical standards of prematurity have been changed over the last two years, consequently any comparisons with

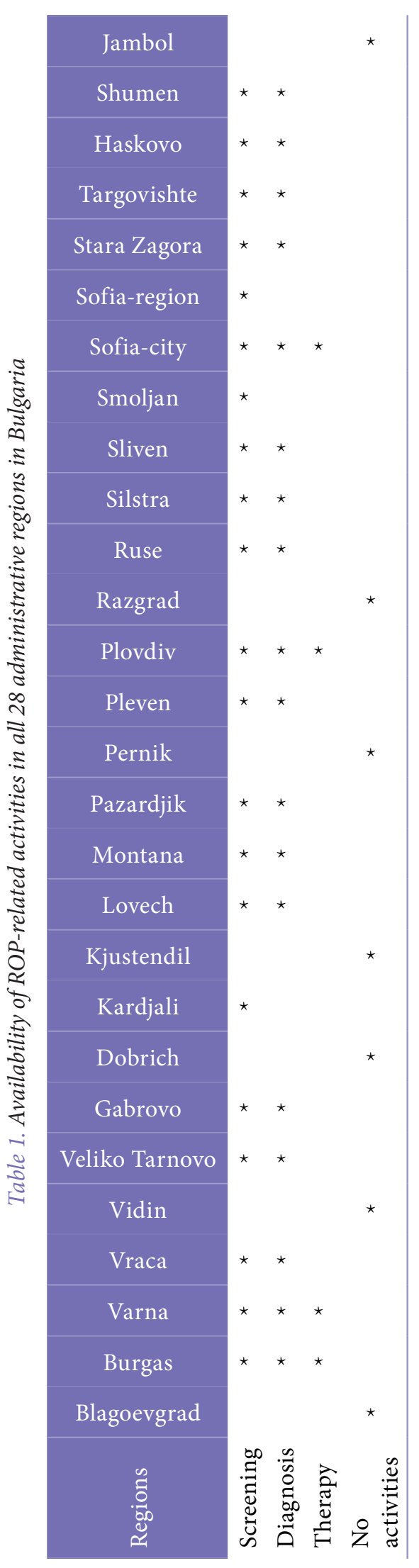


Elena Grozeva, Jana Simova, Desislava Vankova et al.

the former periods of time would be irrelevant (31). There is no official data on incidence and prevalence of ROP among those infants. In order to get a more clear picture of health care infrastructure and procedures, related to ROP, a survey was carried out and a questionnaire was distributed amongst the ophthalmologists from all 28 administrative regions of Bulgaria who are performing ROP screening (Period: April-September, 2015).

The results from the survey indicate that currently the ROP-screening in Bulgaria is performed by an ophthalmologist in the obstetric units (level II or III of competence) or neonatal intensive care units (level III) but eye specialists are not appointed to this units. There are several eye units in Bulgaria, using retinal cameras for screening of ROP. The ROP-screening is performed in 21 administrative units (camera or ophthalmoscopy), while ROP-evaluation for severe or moderate ROP is carried out in only 18 administrative regions. The therapy of preterm babies, related to ROP is carried out in four regions - Burgas, Varna, Plovdiv and Sofia. In seven regions - Blagoevgrad, Vidin, Dobrich, Kjustendil, Pernik, Razgrad and Jambol there are no activities related to ROP-screening and diagnostics. The main reason for that is lack of health care structure and specialists with such competences (see Table 1.).

Types of screening tests used in practice:

Indirect ophthalmoscopy as a screening method performed in 9 regions. Direct ophthalmoscopy is more widely used - in 18 regions. The reasons for that are two: most of the neonatology units have only rudimentary equipment and secondly, some eye doctors are not used to indirect ophthalmoscopy. The two methods for screening of ROP are applied in six regions. Photography of the retina for ROP-screening is reported by the ophthalmologists who work in 5 regions. Telescreening is currently used in one health care unit in Sofia (see Table 2.).

Diagnostics of ROP is performed in health care units in 18 Bulgarian regions. The main diagnostic method is the indirect ophthalmoscopy, which is accepted as a "golden standard" and applied in 10 regions. Fundus photography with retinal cameras is used as a main or compulsory diagnostic method in 7 regions. The health care units, which are not equipped

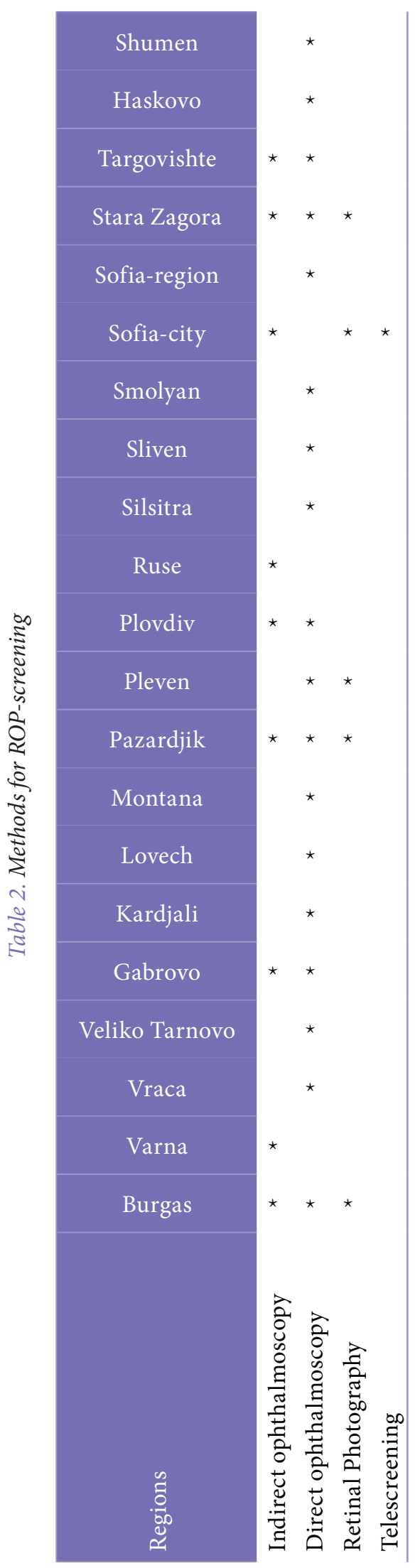

Scripta Scientifica Salutis Publicae, vol. 2, No. 1, 2016, 37-45 


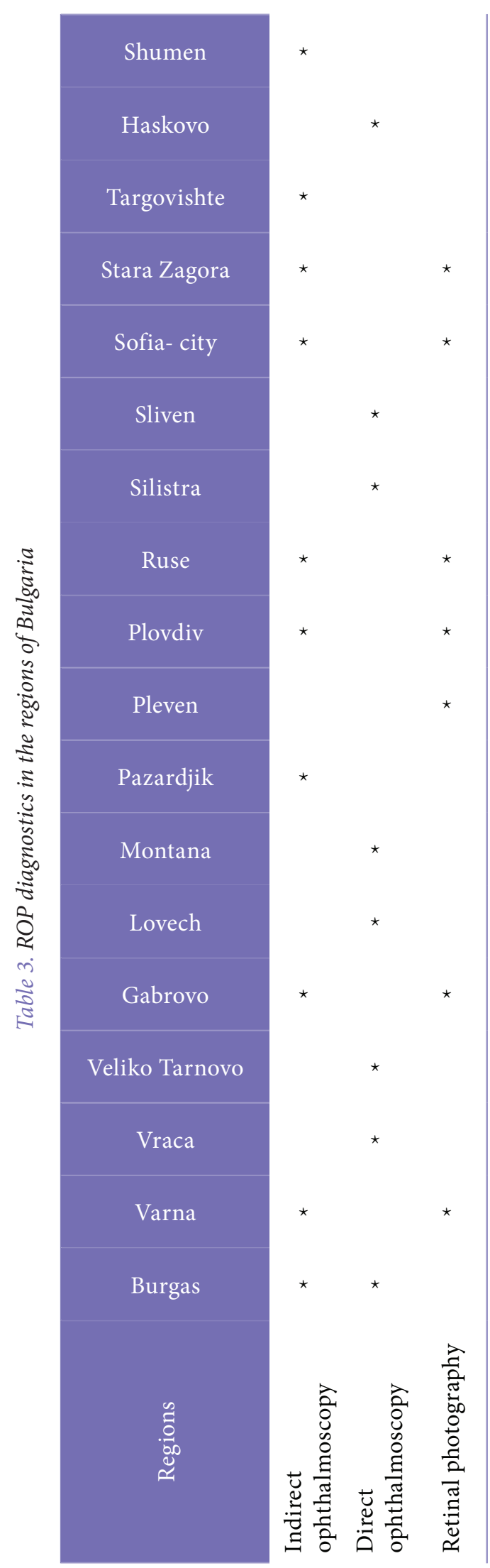

with indirect ophthalmoscopes or retinal cameras, perform direct ophthalmoscopy (see Table 3).

The therapy of the children is carried out only in the cities of Burgas, Varna, Plovdiv and Sofia. In Burgas, cryotherapy is performed, while in the other cities laser therapy is also applied. There is a limited opportunity for anti-VEGF-drug therapy in Bulgaria, only in Sofia, where two units apply it as a treatment of last resort.

Analyses show that the territory of the country where $84.8 \%$ of the population live and $90.4 \%$ of all preterm babies are born, are covered with ROP screening and diagnostic activities but there is no universal accessibility and availability of good quality ROP-health care services. Moreover, the ongoing transformations in our health care system have broken the old centralized system of screening while the new one is still fragile, needs public health support and harmonization with the global developments.

ROP-Discussion and Recommended Strategies

The World Health Organization's Vision 2020 program targets ROP as an "avoidable disease" requiring early detection and treatment to prevent blindness and the inherent costs to the individual and the community $(4,17)$. As described by Vision 2020, recent research has resulted in strategies that have been successful in reducing the incidence of ROP such as routine fundus examination of premature neonates less than 32 weeks' gestation or under $1250 \mathrm{~g}$, provision of carefully monitored levels of supplemental oxygen, where necessary, and treatment and care by well-trained and well-equipped ophthalmologists. As a lower-cost option for developing countries, screening only infants under $1200 \mathrm{~g}$ may be more cost-effective (32). Current treatment options are expensive and can have potentially serious complications (33); thus, prevention is still the best strategy available at present to avoid blindness caused by ROP (25). In Bulgaria, CRYO and LASER therapy are available in 6 centers, and anti-VEGF therapy is associated with some legal problems. In many countries anti-VEGF is the treatment of choice with extremely good results and much less risks in comparison to coagulation.

\section{Public Health Recommendations:}

ROP is a pathological process the progress of which is preventable. This sequential nature of ROP 
Elena Grozeva, Jana Simova, Desislava Vankova et al.

creates a requirement for at-risk preterm infants to be examined at proper times and intervals to detect the changes of ROP before they become permanently destructive. These recommendations present the attributes on which an effective program for detecting and treating ROP could be based, including the timing of the initial examination and subsequent reexamination intervals. According to the International Agency for the Prevention of Blindness (IAPB), public health control and regulations entail improving neonatal care, the delivery of oxygen in particular, and detecting infants who develop the treatable stages of disease, followed by laser to the peripheral retina. These aspects of control are effective at reducing blindness from ROP (34).

Herewith, are presented our public health recommendations concerning ROP-related procedures in Bulgaria. They are formulated after an extensive drill-down of the Bulgarian context and the global developments and will be framed in three main groups as follows:

1. Need for a National Consensus and Registry Database in Bulgaria.

On a national level, there is a need for a National Consensus on the screening and therapy of ROP. Regulations for the development of a National Registry Database, which can be a part of the National Register of Premature Children 2014/2020 could be included in this consensus (35). Although there is no standardized register system, there are several countries which manage national registers on blindness and visual impairments of the age below 19 years: Canada, UK (0-15 years of age), Finland (Finnish Register of Visual Impairments), Kuwait (THE Registry of Visual Impairment Committee), Australia (Australian Childhood Vision Impairment Register - 0-18 years of age) (36). An International Workshop on ROP was organized in 2009 in Varna, Bulgaria, which resulted with a draft for a National Program on Screening and treatment of ROP and it can be used as bases for the above-mentioned health policy instruments.

2. Three-Levels Screening Procedure Proposal.

Effective services for ROP-screening and treatment must be embedded in a robust organizational structure, with the individual responsibilities identified. Particular effort must be made to ensure that the service is delivered appropriately for all those at risk, as there is evidence that babies transferred or discharged home before screening is complete are at risk of poor outcome as a result of a lack of follow-up. A three-level screening procedure is proposed, which is cost-effective and most of the procedures could be performed by the non-physician staff.

* Primary Level - at the neonatology department - screening by a trained physician (neo-natal specialist) on the bases of which it is decided which one of the preterm newborns will be examined on RetCam

* Secondary Level - RetCam - this should also be performed at the neonatal department, and could be done by trained staff.

* Tertiary Level - A specialist overview of the RetCam images and decision for clinical examination, when risk is identified.

In the proposed above three-level screening procedure the role of telemedicine could be pivotal, if it is available.

3. The Telemedicine Approaches.

One of the greatest challenges in less-developed countries is having adequate screening done by ophthalmologists trained to diagnose ROP with indirect ophthalmoscopy. Telemedicine, with the use of digital imaging and fundus photography, may also be a potential strategy for ROP screening in regions where there are few trained ophthalmologists who can manage ROP (26).

The Telemedicine approaches are innovative for identifying babies at greater risk of developing severe ROP, especially those in underserved or remote mountain areas or places with a lack of specialists. Through such approach is possible to accurately detect potentially severe ROP by sending retinal images taken in the neonatology department to an offsite image reading center. Non-physician staff can be responsible for taking the photos, which will be available to trained image readers, who will evaluate whether the babies need to be referred for potential treatment. A study in USA (5) found that this telemedicine approach in identifying severe ROP was about as accurate as regular examinations by an ophthalmologist. The telemedicine approach potentially gives hundreds of premature babies in Bulgaria a greater access to ROP screening. 
Finally, and most importantly, ROP is not a disease that occurs in vacuum; it has many implications for the society. The blindness and visual impairment that are its most feared outcomes are of enormous cost to its victims and to all of us as well. Now we know that a true epidemic is emerging because ROP occurs at a greater frequency than usually expected. Hence, ROP is "unfinished agenda" (3) for ophthalmic and pediatric communities as well as for public health professionals who are responsible for the evidence-based epidemiological research and health policy development. The conclusion is that while significant reductions in the disease rates have occurred in developed countries, further research is required to fully understand and prevent the disease in Bulgaria. In the meantime, development and implementation of appropriate screening and treatment strategies will be critical in reducing blindness in our country.

To sum up, the reasons for this "third epidemic" of ROP have been discussed together with strategies for control, including the need for evidencebased criteria which ensure that all babies in Bulgaria born at risk are examined. Consequently, from a public health perspective, ROP is targeted as an important but avoidable disease.

\section{REFERENCES}

1. Azad, R., Trese, M., Textbook of Retinopathy of Prematurity, 2011, Lippincott Williams \& Wilkins: India.

2. Flynn, J.T. and Tasman, W.S., (eds.), Retinopathy of Prematurity: A Clinician's Guide, 1992: SpringerVerlag New York Inc.\& New York.

3. Gilbert, C., Retinopathy of prematurity: a global perspective of the epidemics, population of babies at risk and implications for control, Early Hum Dev., 2008: Feb; 84(2):77-82. doi: 10.1016/j. earlhumdev.2007.11.009.

4. WHO, Born Too Soon: The Global Action Report on Preterm Birth, 2012: WHO\& Geneva.

5. National Eye Institute, National Institutes of Health, The Telemedicine Approaches to Evaluating Acute-phase ROP (e-ROP) study, available at https://nei.nih.gov/health/rop/rop , 2014; accessed on 01.2016.

6. $\mathrm{MOH}$, Ordinance № 19 from 22 of Dec. 2014 Г. On the New Standards "Obstetrics and Gynecology",
State Gazette (official edition of the National Assembly), issue 106, on 23.12.2014 (Bulgarian).

7. Frederick M. Wilson, II, MD. Practical ophthalmology: A manual for beginning residents., San Francisco, American Academy of Ophthalmology, 1996, 415

8. Sekeroglu MA, Hekimoglu E, Sekeroglu HT, Arslan U. Alternative methods for the screening of retinopathy of prematurity: binocular indirect ophthalmoscopy vs wide-field digital retinal imaging. Eye. 2013;27(9):1053-1057. doi:10.1038/eye.2013.128

9. Castillo-Riquelme M.C., J. Lord, M.J. Moseley, A.R. Fielder, L. Haines. Cost-effectiveness of digital photographic screening for retinopathy of prematurity in the United Kingdom. Int J Technol Assess Health Care. 2004 Spring;20(2):201-13.

10. Seiberth V., C. Woldt. Wide angle fundus documentation in ROP. Ophthalmology, 2001, 98(10): 960-3.

11. Yen KG, D. Hess, B. Burke, R.A. Johnson, W.J. Feuer, J.T. Flynn.Telephotoscreening to detect retinopathy of prematurity: preliminary study of the optimum time to employ digital fundus camera imaging to detectROP. J AAPOS. 2002 Apr;6(2):64-70.

12. Fierson W.M., A. Jr. Capone; AAP, AAO, AACO;Telemedicine for evaluation of retinopathy of prematurity. Pediatrics. 2015 Jan;135(1):e238-54.

13. Field M. Telemedicine: A Guide to Assessing Telecommunications in Health Care. Washington, DC: National Academies Press; 1996

14. Lorenz B, Spasovska K, Elflein H, Schneider N. Wide-field digital imaging based telemedicine for screening for acute retinopathy of prematurity (ROP). Six-year results of a multicentre field study. Graefes Arch Clin Exp Ophthalmol. 2009;247(9):1251-1262pmid:19462177

15. Institute of Medicine, Preterm Birth: Causes, Consequences, and Prevention. Washington, D.C.: National Academy Press, 2007.

16. Zin A, Gole GA., Retinopathy of prematurity-incidence today, 2013: Clin Perinatol., 40:185-200.

17. Gilbert C, Foster A., Childhood blindness in the context of Vision 2020 - the right to sight. Bulletin of World Health Organisation, 2001;79:227-32.

18. Terry TL., Extreme prematurity and fibroplastic overgrowth of persistent vascular sheath behind 
Elena Grozeva, Jana Simova, Desislava Vankova et al.

each crystalline lens. American Journal of Ophthalmology , 1942;25:203-4.

19. Campbell K. Intensive oxygen therapy as a possible cause of retrolental fibroplasia: a clinical approach. Med J Aust., 1951;2:48-50.

20. Hatfield EM. Blindness in infants and young children. Sight Sav Rev 1972; 42:69-89.

21. Avery ME, Oppenheimer EH., Recent increase in mortality from hyaline membrane disease. Journal of Pediatrics, 1960;57:553-9.

22. 22. Gibson DL, Sheps SB, Schechter MT, et al., Retinopathy of prematurity: a new epidemic? Pediatrics 1989; 83:486-92.

23. Phelps DL., Retinopathy of prematurity: an estimate of vision loss in the United States-1979. Pediatrics, 1981: 67:924-6.

24. Keith CG, Doyle LW, Kitchen WH, et al., Retinopathy of prematurity in infants of 24-30 weeks' gestational age. Med J Aust 1989; 150:293-6.

25. Wheatley, C. M., Dickinson, J. L., Mackey, D. A., Craig, J. E. , Sale M. M., Retinopathy of prematurity: recent advances in our understanding, $\mathrm{Br} J$ Ophthalmol., 2002;86:696-701.

26. American Academy of Ophthalmology, Retinopathy of Prematurity- Epidemiology, 2015: http:// www.aao.org/topic-detail/retinopathy-of-prematurity, accessed on 6-01-2015.

27. RCPCH (Expert group of Royal College of Paediatrics and Child Health, Royal College of Ophthalmologists British Association of Perinatal Medicine \& BLISS), UK Retinopathy of Prematurity Guideline, 2008: Royal College of Paediatrics and Child Health: UK

28. Pandova, M., Feschieva, N., Mircheva, I., Methodological Considerations in Population-based studies of Blindness and Low Vision, Vol. 10, Suppl. 3, 12-17, 2012.

29. Nikolova, S., Kontrova, E., Zlatarova, Z et al., Retinopatia na nedonosenoto- rezultati ot screening I lechenie za 12 godishen period. Referativen Buletin N 6; 2009: 27-32.

30. Marinov, V., Sivkova,N., Boeva, J., Retinoaptia na nedonosenoto v Plovdiv I regiona- parvonachalni nabljudenia, Referativen Buletin po oftalmologia, N 4; 2011: 34-41.

31. National Center of Public Health and Analyses, Data provided by NCPHA especially for a PhDproject "Prichini za namaleno zrenie I za slepota sred decata, rodeni nedonoseni v Starozagorski region” Department of Ophthalmology, MU-Varna, 12 Nov.2015, Sofia.

32. Lee SK, Normand C, McMillan D, et al. Evidence for changing guidelines for routine screening for retinopathy of prematurity. Arch Pediatr Adolesc Med 2001;155:387-95.

33. Whitfill CR, Drack AV. Avoidance and treatment of retinopathy of prematurity. Sem Pediatr Surg 2000;9:103-5.

34. IAPB, the International Agency for the Prevention of Blindness, Leading Blindness Prevention Efforts Worldwide, accessed on 08.2015, http://www.iapb. org/adults-over-50-map

35. Council of Ministers, Национална програма за подобряване на майчиното и детското здраве 2014-2020 г. Национална здравна стратегия 2014-2020 на Министерския съвет на Република България.

36. Nencheva, B., Zrenie 20/20 mit ili realnost, 2015, Mu-Varna, Steno: Varna. 